\title{
Research on the Development of Rural Tourism in Jilin Province Under the Coordination of "Industrialization, Urbanization and Agricultural Modernization"*
}

\author{
Haoliang Sun \\ Yatai School of Business Administration \\ Jilin University of Finance and Economics \\ Changchun, China 130017
}

\author{
Xiangjun Meng \\ Yatai School of Business Administration \\ Jilin University of Finance and Economics \\ Changchun, China 130017
}

\begin{abstract}
The realization of the coordination of "industrialization, urbanization, and agricultural modernization" is the strategic task of the 13th Five-Year Plan of Jilin Province. Under the background of the active promotion of the "three-dimensional overall planning", as a traditional agricultural province, Jilin Province has a large space for developing rural tourism, which is not only in line with policy advocacy and has broad market prospects, but also one of the most direct and effective ways to solve the issue of agriculture, rural areas and rural residents. We can combine rural tourism and beautiful rural construction organically; transform rural tourism resources into benefits, promote beautiful rural construction, and then repay the development of rural tourism with beautiful rural construction to develop a "Jilin Road" suitable for its own development, thus achieving the vision of sustainable development of rural tourism in Jilin.
\end{abstract}

Keywords-Jilin Province; rural tourism; market development

\section{INTRODUCTION}

According to the new characteristics of China's social and economic development and the new requirements for solving the issue of "agriculture, rural areas and rural residents", Jilin Province proposed to "coordinately promote industrialization, urbanization and agricultural modernization, and strive to form a new pattern of integration of urban and rural economic and social development." This is also a new strategic decision made to achieve common development of urban and rural areas, which puts forward new requirements for solving the problem of "agriculture, rural areas and rural residents" with the concept of coordinating urban and rural development. Vigorously promoting urbanization, industrialization and agricultural modernization is of great

*Fund Project:

1. Jilin Development and Reform Commission Project: Jilin Province Service Industry Development Report

2. Jilin Provincial Department of Education "Twelfth Five-Year Plan" Social Science Research Planning Project, Project Name: Research on Sustainable Development of Rural Tourism in Jilin Province under the Coordination of "Industrialization, Urbanization and Agricultural Modernization" (No. 0803521501). significance for accelerating the formation of a new pattern of "industrialization, urbanization, and agricultural modernization" in rural areas. It is a major strategic decision made by Jilin Provincial Party Committee and the provincial government from the realistic historical stage of Jilin Province to coordinately promote the development of "industrialization, urbanization, and agricultura modernization" in rural areas and promote urbanization construction to walk on a new path of interactive development of industrialization, urbanization and agricultural modernization with Jilin characteristics, which is also a big article in the overall layout of economic and social development in Jilin Province.

\section{THE SIGNIFICANCE OF DEVELOPING RURAL TOURISM}

\section{A. Opening Channels for Increasing Farmers' Income}

Rural tourism is the tourism activity that combines agricultural tourism, eco-tourism, rural leisure, farmhouse enjoyment and folk customs experience, which is carry out by making full use of rural resources. Rural areas inherently have good customs, natural landscapes, pastoral scenery, natural ecological environment and agricultural resources, which lay a good foundation for the development of rural tourism. According to these congenital natural conditions, people in rural areas can directly participate in the development of tourism products and the construction of scenic spots, increase tourism attractions in rural areas, change the model of rural economic development, promote the adjustment of rural industrial structure, and build broader channel for increasing the income of farmers.

\section{B. Providing Employment Opportunities for Farmers}

International Tourism Organization research shows that every additional employment opportunity in the tourism industry can provide jobs for 6-8 employees in the society, and the multiplier effect is huge. Located in the northeastern region, Jilin Province is a famous agricultural province with a large agricultural population. With the rapid development of agricultural modernization, the rural surplus labor force 
has gradually increased. The exploitation and development of rural tourism has changed the face of rural areas while promoting the development of rural economy. The construction of infrastructure and sustainable development of tourism has provided more employment opportunities for farmers.

\section{Conducive to Improving the Overall Quality of Farmers}

The group faced by rural tourism is urban tourists. Due to the difference between rural and urban areas, tourists from different places come to rural tourism. While they are feeling the natural scenery, folk customs and local flavor of the countryside, the two cultures blend with each other, which have certain influences on the construction, production and management in rural areas. At the same time, bringing advanced ideas and concepts of the city into the countryside will raise higher requirements for agricultural producers and managers as well as promote farmers to constantly update their concepts and improve service awareness and service level and recognize the importance of learning scientific and cultural knowledge and advanced management knowledge, which is conducive to improving the overall quality of farmers.

\section{Conducive to Promoting the Construction of Rural Urbanization}

The development of urbanization is the only way to completely narrow the gap between the rich and the poor in urban and rural areas and solve the dual structure of urban and rural areas in China. Relevant research shows that every $1 \%$ of rural population moving to urban areas will increase national consumption by $0.1 \%-0.34 \%$; every $1 \%$ of rural labor transferring to non-agriculture will increase CDP by $0.50 \%-0.85 \%$, which means the increase in total income of population engaged in agriculture. With the continuous development of rural production technology, the surplus labor force in rural areas has also increased. Urbanization construction can not only realize the transfer of rural surplus labor, but also achieve coordinated development of urban and rural areas and promote social stability and harmony.

\section{THE PROBLEMS OF RURAL TOURISM IN JILIN PROVINCE}

\section{A. The Lack of Scientific and Rational Planning}

Scientific and rational planning is the basic condition for the development of rural tourism. However, many rural villages have seriously damaged the unique tourism resources when developing tourism. They do not consider the objective reality and the rules of the tourism market but blindly follow others, leading to the lack of coordination and repeated construction. Some tourism developers only pay attention to planning, but they ignore the value of the original eco-tourism resources, such as quiet country roads and rural scenery in the sunset. They are lacking in the concept of rural tourism development of having those others don't have, doing best in those others also have and making innovation in those others can do best in", so they just imitate the developed villages of other rural tourism. They haven't clearly realized that it is important for rural tourism planning to not only protect its own resources, but also develop its own resource advantages.

\section{B. The Design of the Scenic Spot Lacks Features, and the Marketing Is Not in Place}

Individualization and specialization are the development trend of tourism in the future. However, in the process of rural tourism development, Jilin Province does not make scientific and rational design according to the natural conditions and resource advantages of the village and neglect the individualized and specialized research and development of tourism products. So it didn't form its own distinctive rural tourism products. The service content and projects provided for tourists are similar, which is difficult to meet the different needs of urban tourists and restricts the development of rural tourism in Jilin Province. In addition, tourism goods such as handmade art are not abundant and not integrated into the development of rural tourism. Moreover, rural tourism carries out the design and promotion of tourism brands without fully considering the characteristics of the tourist market, so the popularity is low, which makes it difficult for it to radiate to remote areas. The main body of the expansion of rural tourism market should be residents of big cities who have strong consuming ability and strong desire for consumption. However, because the propaganda is not in place and the developers of rural tourism don't have clear market positioning, some rural-urban fringe zone are included in the market scope. In fact, they do not have much desire for consumption in rural tourism and only focus on visiting relatives, but potential consumers in large cities rarely know about the tourism.

\section{Imperfect Tourism Infrastructure and Low Comprehensive Economic Benefits}

Tourism is a comprehensive service industry, involving eating, lodging, traveling, touring, shopping, and entertainment and so on, so there must be corresponding tourism facilities in the tourist destination. In the survey, it is found that the number of tourist facilities in rural areas is not only very small, but also not optimistic in terms of quality. There is no complete industrial service chain, and products and services are less extended. The most basic food and accommodation in tourism cannot be guaranteed. It is not uncommon for tourists to travel in rural areas and then eat and live back home, which leads to low comprehensive economic benefits. In addition, sanitary conditions still need to be improved.

\section{The Quality and Service Quality of Employees Are Not Enough}

Most of the rural tourism practitioners are villagers. They have not undergone good vocational training, so they lack professional service skills and service awareness. They cannot think of what consumers think in the service process and solve the problem of consumers in a timely manner. In the working process, they can't discover the problem in time, and judge the future service trend to make update and improvement, which leads to the lag of service quality; the 
satisfaction of tourists is low, and the tourism revisit rate is reduced.

\section{STRATEGIES FOR THE DEVELOPMENT OF RURAL TOURISM IN JILIN PROVINCE UNDER THE OVERALL PLANNING OF "INDUSTRIALIZATION, URBANIZATION, AND AGRICULTURAL MODERNIZATION"}

\section{A. Promoting Infrastructure Construction and Extending the Industrial Chain}

The construction of infrastructure is related to the followup development momentum of rural tourism, which is an important guarantee for promoting the development of rural tourism market. Infrastructure construction includes transportation, tourist accommodation, restaurants, entertainment venues and necessary facilities matching the scenic spots. The infrastructure should be coordinated with the rural environment, so that the infrastructure can also become a tourism resource, reflecting the characteristics of rural tourism culture. For the relatively large initial investment in infrastructure, the government should play a leading role, organize experts to carry out preliminary planning and deployment, and do some necessary infrastructure in advance, which has certain advancement. At the same time, it is necessary to give certain financial support in policy, guide farmers to understand the importance of infrastructure construction, and fully mobilize the enthusiasm of farmers to develop rural tourism. In addition, the society should be encouraged to actively participate in the construction, expand financing channels, and play the role of social capital in rural tourism infrastructure.

\section{B. Creating Distinctive Brands and Developing Creative Tourism Products}

1) Creating a distinctive brand: At present, the development trend of rural tourism in China is from the recreation and sightseeing to the leisure resort, emphasizing the experience in rural tourism, and the brand characteristics are the foundation and soul of the rural tourism experience. Personalized and connotative rural tourism brands can avoid the homogenization and simplification of rural tourism services and products while enhancing the experience psychology of tourists. Accordingly, Jilin Province should focus on building the industrial chain of rural tourism, thereby increasing the overall economic benefits of rural tourism. First, through various experiential and personalized services, we can enhance the leisure function of rural tourism, increase the tourist's revisiting rate while extending the stay time of tourists. Secondly, we can expand and deepen the existing tourism-type rural tourism products, paying attention to quality and improving participation. Jilin Province is a demonstration province for national ecological construction as well as a large agricultural province in China. Under the overall situation of "industrialization, urbanization, and agricultural modernization", it develops agricultural and rural tourism to promote the development of industrialization, urbanization and agricultural modernization. Therefore, Jilin Province can fully exploit and rationally use the rural tourism sites in the province, and develop organic farming and picking industry to form an order-based development and satisfy customers' food safety. Rural creative tourism has broad development prospects, so we can establish a brand of rural tourism and enhance customer awareness to achieve personalized development.

2) Developing special tourism products: Innovation is the primary productivity of development. We should encourage the development of innovative and distinctive tourism products, strengthen the exploitation of rural tourism products, and strive to deepen the development of rural tourism, transforming rural tourism forms from sightseeing to leisure. Learning from the successful experience of rural ecotourism in developed countries, such as France that develops specialty farms, Netherlands that focus on culturing flowers, and Germany that pays attention to service quality, etc., we can use the unique advantages to attract more tourists to travel. In the development of rural tourism, Jilin Province should combine its own resource advantages and the cultural connotations to develop distinctive tourism products, create different thematic environments, highlight ethnic and folk customs and rural cultural atmosphere, and develop cultural products with distinctive features to meet the different needs of tourists. They can combine with human resources, and excavate unique cultural materials to enhance cultural taste. For example, the development of green fishing parks, ice and snow festivals, ethnic villages, hot spring baths, ecological parks, winter fishing festivals and other local tourism projects and products can make tourists forget to leave.

\section{Strengthening Team Building and Improve Service Quality}

1) Scientific planning to improve service levels: The development of "industrialization, urbanization, and agricultural modernization" requires the coordinated development of industrialization, urbanization and rural modernization. In order to achieve sustainable development of rural tourism in Jilin Province, it is necessary to adhere to the scientific planning of rural tourism, integrate the existing rural tourism resources and make scientific and rational planning and development, to highlight the regional characteristics and customs, maintain the local culture, natural scenery and traditional culture, and achieve the development of differentiation in rural tourism. Government departments should gradually build and improve the service reception system for rural tourism, improve the classification standards for rural tourism, achieve standardized management and operation, and improve the service quality and service level of rural tourism to make operators form the concept of "legitimate management and honest service". 
2) Strengthening the training of employees and cultivate professional talents: High-quality talents and professional managers are the main driving forces for rural tourism. Therefore, strengthening the quality of managers and employees of rural tourism, enhancing service awareness and improving service quality are extremely important aspects of developing rural tourism. First, we can organize rural tourism managers and relevant practitioners to visit and study in successful scenic spots, use successful scenic spots as a template, learn good management experience and advanced management concepts, and develop local rural tourism according to local conditions; second, we should organize personnel to study in tourism management specialization institutions to learn and perfect professional skills and professional knowledge; Third, the tourism area can hire relevant scholars and experts to visit the tourist destinations and conduct comprehensive and systematic planning of the development and construction of rural tourism, and provide guidance and training for service levels, professional skills and service awareness of service personnel. Through continuous training and learning, we can improve the quality of rural tourism practitioners and managers, improve the service level of service personnel, enhance their service awareness, and continuously promote the sustainable development of rural tourism.

\section{Giving Full Play to the Role of the Government Management Department}

1) The guiding role of government departments: The rapid development of rural tourism has led to the continuous expansion of tourism, leading to an increase in the number of tourists, but collective management has often slowed the development of tourism. Therefore, the government should promptly intervene to play the government's functions, standardize the management of rural tourism development, implement a rating system, continuously guide and encourage farmers to carry out independent operations through the network, and create a network information platform to enable farmers to more easily engage in business activities and learn professional knowledge.

2) Supporting role of government departments: Government support has always been a necessary condition for promoting the survival and development of enterprises. The development of rural tourism is also inseparable from the support of government departments. The government can regulate the development of the rural tourism market by introducing legislation and continuously improving relevant policies, regulations and methods. They can give full play to the functions of government management departments, establish sound laws and regulations, provide financial and policy support for the development of rural tourism, and promote the construction of public service facilities such as rural tourism consulting services, rural tourism rescue services, rural tourism complaints handling, and rural tourism insurance services, enhance the safety and convenience of tourists' rural tourism consumption, and formulate and continuously improve laws and regulations to ensure the legitimate rights and interests of tourists.

3) Coordination of government departments: Only by realizing the balance of interests can we guarantee the longterm existence of the industrial organization model, and the premise of sustainable interests is to maintain the authenticity and persistence of rural tourism. The government provides funds through the introduction of policies to protect the authenticity of rural tourism, and coordinate the interests of all parties to promote the development of rural tourism.

\section{CONCLUSION}

For a long time, the coordination of "industrialization, urbanization, and agricultural modernization" has always been the focus of government departments. The development of China's tourism industry has also seen many new forms of tourism, and rural tourism faces a rare opportunity. Achieving the co-ordination of "industrialization, urbanization, and agricultural modernization" also realizes the organic integration of agriculture and tourism, and promotes the overall level of rural tourism. The development of rural tourism drives economic growth and raises the economic level of the population in rural areas, thus making urbanization, industrialization and agricultural modernization develop better and faster. To promote the development of rural tourism in Jilin Province with the "industrialization, urbanization, and agricultural modernization" and then to feed the "industrialization, urbanization, and agricultural modernization" through the development of rural tourism will surely be a road for the characteristic development of Jilin Province.

\section{REFERENCES}

[1] Zhang Wen, An Yanyan, Li Na. Social and Economic Benefits, Problems and Countermeasures of Rural Tourism Development in China[J]. Journal of Beijing International Studies University, Journal of Beijing International Studies University, 2006(03).

[2] Li Jinrong, Zhang Xinmu, Han Bo. A Brief Discussion on the Development of Rural Community Tourism in Jilin Province[J]. Changbai Journal, 2012(2).

[3] Sun Haoliang. Research on the Status Quo and Development Countermeasures of Rural Tourism in Jilin Province[J]. Foreign Economic Relations \& Trade, 2015(9).

[4] Fu Hui. Research on the Development of Agricultural Eco-tourism in Jilin Province China[J]. China Agriculture Information, 2014.10 (45).

[5] Zhou Jie, Yuan Chunzhen. Reflections on the Sustainable Development of Rural Tourism Based on the Construction of New Socialist Countryside[J]. Journal of Shandong Agricultural University (Natural Science Edition). 2008(1).

[6] Wen Nianjing. Research on the Development of Rural Tourism in Jilin Province from the Perspective of Urban and Rural Coordination[D]. Northeast Normal University, 2012.6.

[7] Chuan Yangyang. Analysis on the Countermeasures to Improve the Rural Economy Based on the Development of Rural Tourism[J]. Scientific Management, 2014 (05). 